\title{
A Particle Swarm Intelligence based Fuzzy Time Series Forecasting Model
}

\author{
Jilani T. A., Burney S.M.A., Amjad U. \\ Department of Computer Science, \\ University of Karachi, \\ Karachi-Pakistan.
}

\author{
Tanveer A. Siddiqui \\ Department of Mathematics \\ University of Karachi \\ Karachi-Pakistan.
}

\begin{abstract}
In this paper, we have presented a new particle swarm optimization based multivariate fuzzy time series forecasting method. This method assumes five-factors with one main factor of interest. History of past three years is used for making new forecasts. This new method is applied in forecasting total number of car accidents in Belgium using four secondary factors. We also make comparison of our proposed method with existing methods of fuzzy time series forecasting. Experimentally, it is proved that our proposed method perform better than many existing fuzzy time series forecasting methods. The interest of this paper centers in applying swarm intelligence approaches in forecasting related problems. The dataset is taken from National Institute of Statistics, Belgium.
\end{abstract}

\section{General Terms}

Nature inspired computing, Time series forecasting

\section{Keywords}

Average forecasting error rate (AFER), Fuzziness of fuzzy sets, Fuzzy If-Then rule, particle swarm optimization (PSO).

\section{INTRODUCTION}

During last few decades, various approaches have been developed for time series forecasting. Among them ARMA models and Box-Jenkins model building approaches are highly famous. In recent years, many researchers used fuzzy time series to handle prediction problems. Song and Chissom [1] presented the concept of fuzzy time series based on the concepts of fuzzy set theory to forecast the historical enrollments of the University of Alabama. Huarng [2] presented the definition of two kinds of intervals in the universe of discourse to forecast the TAIFEX. Chen [3] presented a method for forecasting based on high-order fuzzy time series. Lee [4] presented a method for temperature prediction based on two-factor high-order fuzzy time series. Melike [5] proposed forecasting method using first order fuzzy time series for forecasting enrollments in University of Alabama. Lee [4] Presented handling of forecasting problems using two-factor high order fuzzy time series for TAIFEX and daily temperature in Taipei, Taiwan. In ([6], [7], [8], [9]), Jilani and Burney presented a number of new fuzzy metrics for multivariate fuzzy time series forecasting for car road casualties data, Taipei temperature data and enrollments data problem of University of Alabama.

The rest of this paper is organized as follows. In section 2, brief review of fuzzy time series is given. In section 3 and 4 , brief review on nature inspired computing and particle swarm optimization is given. Our proposed PSO based FTS method is given in section 5. Experimental results are performed in section 6 . The conclusions are discussed in section 7 .
In this paper, we present a new modified method to predict total number of annual car road accidents based on the $\mathrm{m}$ factors high-order fuzzy time series. This method provides a general framework for forecasting that can be increased by increasing the stochastic fuzzy dependence ([10], [11]). For simplicity of computation, we have used triangular membership function. The proposed method constructs $\mathrm{m}$ factor high-order fuzzy logical relationships based on the historical data to increase the forecasting accuracy rate. Our proposed forecasting method for fuzzy time series gives better results as compared to Lee, Wang, Chen [4], Chen [3], and Jilani and Burney ([6], [7], [8], [9]). Table 1 shows yearly car accidents mortalities from 1974 - 2004 for Belgium.

\section{FUZZY TIME SERIES}

Most of the real life problems are born with uncertainty, therefore, each observation of a fuzzy time series is assumed to be a fuzzy variable along with associated membership function. Based on fuzzy relation, and fuzzy inference rules, efficient modeling and forecasting of fuzzy time series is possible, ([12], [13]). This field of fuzzy time series analysis is not very mature due to the time and space complexities, thus we can extend this concept for many antecedents and single consequent. For example, in designing two-factor kthorder fuzzy time series model with $\mathrm{X}$ be the primary and $\mathrm{Y}$ be second fact. We assume that there are $\mathrm{k}$-antecedent $\left(\left(X_{1}, Y_{1}\right),\left(X_{2}, Y_{2}\right), \ldots,\left(X_{k}, Y_{k}\right)\right)$ and one consequent $X_{k+1}$.

$$
\text { If }\left(X_{1}=x_{1}, Y_{1}=y_{1}\right),\left(X_{2}=x_{2}, Y_{2}=y_{2}\right), \ldots,\left(X_{k}=x_{k}, Y_{k}=y_{k}\right) \rightarrow\left(X_{k+1}=x_{k+1}\right)
$$

In the similar way, we can define $\mathrm{m}$-factor $\mathrm{i}=1,2, \ldots, \mathrm{m}$ and $\mathrm{kth}$ order fuzzy time series as

$$
\begin{aligned}
& \text { If }\left(X_{11}=x_{11}, X_{12}=x_{12}, \ldots, X_{1 k}=x_{1 k}\right), \\
& \left(X_{21}=x_{21}, X_{22}=x_{22}, \ldots, X_{2 k}=x_{2 k}\right), \ldots, \\
& \left(X_{m 1}=x_{m 1}, X_{m 2}=x_{m 2}, \ldots, X_{m k}=x_{m k}\right) \\
& \text { then }\left(X_{m+1}, k+1=x_{m+1 k+1}\right) \\
& \text { for } i=1,2, \ldots, m, j=1,2, \ldots, k
\end{aligned}
$$

Formally, the proposed method is given in section 5 .

\section{NATURE INSPIRED COMPUTING}

Nature Inspired Computing (NIC) is a type of computing technique that gets ideas by understanding how nature deals in various situations to solve complex problems ([14]). Research on NIC has opened new branches such as evolutionary computation, artificial immune systems, swarm intelligence, and so on. The improvement in the computer hardware and 
massive increase in the computational power have made the emergence of nature inspired computing possible. That's why NIC techniques are implemented in many fields like biology, physics, engineering, economy, management, and so on. Many different types of models like swarms, colonies, or other natural metaphors have been developed which can help us to model extremely complex and dynamic systems.

Table 1. Yearly Car Accidents Mortalities and Victims from 1974 to 2004

\begin{tabular}{cccccc}
\hline Year & $\begin{array}{c}\text { Killed } \\
(\mathrm{X})\end{array}$ & $\begin{array}{c}\text { Mortally } \\
\text { wounded } \\
(\text { Y1) }\end{array}$ & $\begin{array}{c}\text { Died 30 } \\
\text { days } \\
(\text { Y2) }\end{array}$ & $\begin{array}{c}\text { Severely } \\
\text { wounded } \\
(\text { Y3) }\end{array}$ & $\begin{array}{c}\text { Light } \\
\text { casualties } \\
(\text { Y4) }\end{array}$ \\
\hline 2004 & 953 & 141 & 1,094 & 5,949 & 41,627 \\
2003 & 1,035 & 101 & 1,136 & 6,898 & 42,445 \\
2002 & 1,145 & 118 & 1,263 & 6,834 & 39,522 \\
2001 & 1,288 & 90 & 1,378 & 7,319 & 38,747 \\
2000 & 1,253 & 103 & 1,356 & 7,990 & 39,719 \\
1999 & 1,173 & 126 & 1,299 & 8,461 & 41,841 \\
1998 & 1,224 & 121 & 1,345 & 8,784 & 41,038 \\
1997 & 1,150 & 105 & 1,255 & 9,229 & 39,594 \\
1996 & 1,122 & 115 & 1,237 & 9,123 & 38,390 \\
1995 & 1,228 & 109 & 1,337 & 10,267 & 39,140 \\
1994 & 1,415 & 149 & 1,564 & 11,160 & 40,294 \\
1993 & 1,346 & 171 & 1,517 & 11,680 & 41,736 \\
1992 & 1,380 & 173 & 1,553 & 12,113 & 41,772 \\
1991 & 1,471 & 209 & 1,680 & 12,965 & 43,578 \\
1990 & 1,574 & 190 & 1,764 & 13,864 & 46,818 \\
1989 & 1,488 & 312 & 1,800 & 14,515 & 46,667 \\
1988 & 1,432 & 339 & 1,771 & 14,029 & 45,956 \\
1987 & 1,390 & 380 & 1,770 & 13,809 & 44,090 \\
1986 & 1,456 & 330 & 1,786 & 13,764 & 42,965 \\
1985 & 1,308 & 352 & 1,660 & 13,287 & 39,879 \\
1984 & 1,369 & 363 & 1,732 & 14,471 & 42,456 \\
1983 & 1,479 & 412 & 1,891 & 14,864 & 42,023 \\
1982 & 1,464 & 406 & 1,870 & 14,601 & 40,936 \\
1981 & 1,564 & 454 & 2,018 & 15,091 & 41,915 \\
1980 & 1,616 & 557 & 2,173 & 15,915 & 42,670 \\
1979 & 1,572 & 544 & 2,116 & 15,750 & 42,346 \\
1978 & 1,644 & 728 & 2,372 & 16,645 & 44,797 \\
1977 & 1,597 & 701 & 2,298 & 15,830 & 44,995 \\
1976 & 1,536 & 728 & 2,264 & 16,057 & 44,227 \\
1975 & 1,460 & 701 & 2,161 & 15,792 & 42,423 \\
1974 & 1,574 & 819 & 2,393 & 16,506 & 44,640
\end{tabular}

NIC helps us understand the underlying mechanism of a realworld complex system by formulating computing models and testing hypotheses through controlled experimentation ([15], [16]). The end product of such computing experiments is a deep understanding or a new discovery of the real working mechanism of the modeled system. NIC also enables us to embody autonomous (e.g., life-like) behavior in solving computing problems. With detailed knowledge of the underlying mechanism, abstracted autonomous behavior can be used as a model for a general-purpose problem-solving strategy or method. Self-organization is the essential process of its working mechanism. Through the local interactions, an NIC system self-aggregates and amplifies the outcome of entity behavior.

\section{PARTICLE SWARM OPTIMIZATION}

Particle Swarm Optimization is a computational method that optimizes a problem by iteratively trying to improve a candidate solution with regard to a given measure of quality ([17]). PSO optimizes a problem by having a population of candidate solutions, here dubbed particles, and moving these particles around in the search space according to simple mathematical formulae over the particles position and it is also guided toward the best known position in the search space, which are updated as better positions are found by other particles.

PSO could be explained well in an imagined scenario: a group of birds are flying in an area to look for food, and there's only one piece of food in this area. Each bird in the group doesn't know the exact location of the food, but they are aware of the distance between the food and themselves. In this way, the easiest way to find the food is to follow the one who is closest to the food. When it comes to the algorithm of PSO, it starts with the initialization of a population of random particles, each of which is associated with a position and a velocity. The velocities are adjusted according to the historical behavior of each particle and its neighbors while they fly through the search space. The positions are updated according the current position and the velocities at the next step ([18]). Therefore, the particles have a tendency to fly towards the better and better search area over the search process course. Initially, some particle is identified as the best particle in a neighborhood of particles, based on its fitness. All the particles are then accelerated in the direction of this particle, but also in direction of their own best solutions that they have discovered previously.

In other words we can say that the core concept of PSO lies in accelerating each particle toward its pbest which was achieved so far by that particle, and the gbest which is the best value obtained so far by any particle in the neighborhood of that particle, with a random weighted acceleration at each time step. A particle's velocity and position are updated as follows.

$$
v_{i}^{(t+1)}=w^{(t)} \times v_{i}^{(t)}+c_{1} \times r_{1} \times\left(\text { pbest }-x_{i}^{(t)}\right)+c_{2} \times r_{2} \times\left(\text { gbest }-x_{i}^{(t)}\right)
$$

$X^{(t+1)}=X^{(t)}+v^{(t+1)}$

Where $\mathrm{X}$ and $\mathrm{V}$ are position and velocity of particle respectively. $\mathrm{W}$ is inertia weight, $\mathrm{c} 1$ and $\mathrm{c} 2$ are positive constants, called acceleration coefficients which control the influence of pbest and gbest on the search process, $\mathrm{P}$ is the number of particles in the swarm, $\mathrm{r} 1$ and $\mathrm{r} 2$ are random values in range $[0,1]$.

The Basic Algorithm for PSO is as under:

1. Create a 'population' of particles uniformly distributed over $X$.

2. Initialize every particle.

3. Calculate fitness value for each particle.

4. If current fitness value of a particle is better than the personal best (pbest) of particle set this as pbest.

5. Choose the particle with the best fitness value of all particle as the global best (gbest).

6. Update particles velocities according to equation 3. 
7. Move particles to their new positions according to equation 4.

\section{Go to step 2 until stopping criteria are satisfied.}

PSO has some drawbacks, such as when the search space is high its convergence speed becomes very slow near global optimum. Another drawback is its nature to a fast and premature convergence in mid optimum points.

\section{NEW METHOD FOR FORECASTING USING FUZZY TIME SERIES AND PARTICLE SWARM OPTIMIZATION}

Let $\mathrm{Y}(\mathrm{t}),(t=\ldots, 0,1,2, \ldots)$ be the universe of discourse and $Y(t) \subseteq R$. Assume that $f_{i}(t), i=1,2, \ldots$ is defined in the universe of discourse $\mathrm{Y}(\mathrm{t})$ and $F(t)$ is a collection of $\mathrm{f}\left(\mathrm{t}_{\mathrm{i}}\right),(i=\ldots, 0,1,2, \ldots)$, then $F(t)$ is called a fuzzy time series of $\mathrm{Y}(\mathrm{t}), i=1,2, \ldots \ldots$ Using fuzzy relation, we define $F(t)=F(t-1) \circ R(t, t-1)$, where $R(t, t-1)$ is a fuzzy relation and " $O$ " is the max-min composition operator, then $F(t)$ is caused by $F(t-1)$ where $F(t)$ and $F(t-1)$ are fuzzy sets. For forecasting purpose, we can define relationship among present and future state of a time series with the help of fuzzy sets. Assume the fuzzified data of the $i$ th and $(i+1)$ th day are $A_{j}$ and $A_{k}$, respectively, where $A_{j}, A_{k} \in U$, then $A_{j} \rightarrow A_{k}$ represented the fuzzy logical relationship between $A_{j}$ and $A_{k}$.

Let $F(t)$ be a fuzzy time series. If $F(t)$ is caused by $F(t-1), F(t-2), \ldots, F(t-n)$, then the fuzzy logical relationship is represented by

$F(t-n), \ldots, F(t-2), F(t-1) \rightarrow F(t)$

is called the one-factor nth order fuzzy time series forecasting model. Let $F(t)$ be a fuzzy time series. If $F(t)$ is caused by $\left(F_{1}(t-1), F_{2}(t-1)\right),\left(F_{1}(t-2), F_{2}(t-2)\right), \ldots,\left(F_{1}(t-n), F_{2}(t-n)\right)$, then this fuzzy logical relationship is represented by

$\left(F_{1}(t-n), F_{2}(t-n)\right), \ldots,\left(F_{1}(t-2), F_{2}(t-2)\right),\left(F_{1}(t-1), F_{2}(t-1)\right) \rightarrow F(t)$

is called the two-factors nth order fuzzy time series forecasting model, where $F_{1}(t)$ and $F_{2}(t)$ are called the main factor and the secondary factor fuzzy time series' respectively. In the similar way, we can define $\mathrm{m}$-factor $\mathrm{nth}$ order fuzzy logical relationship as

$$
\begin{aligned}
& \left(F_{1}(t-n), F_{2}(t-n), \ldots, F_{m}(t-n)\right), \ldots, \\
& \left(F_{1}(t-2), F_{2}(t-2), \ldots, F_{m}(t-2)\right), \\
& \left(F_{1}(t-1), F_{2}(t-1), \ldots, F_{m}(t-1)\right) \rightarrow F(t)
\end{aligned}
$$

Here $F_{1}(t)$ is called the main factor and $F_{2}(t), F_{3}(t), \ldots, F_{m}(t)$ are called secondary factor fuzzy time series'. Here we can implement any of the fuzzy membership function to define the fuzzy time series in above equations. Comparative study by using different membership functions is also possible. We have used triangular membership function due to low computational cost. Using fuzzy composition rules, we establish a fuzzy inference system for fuzzy time series forecasting with higher accuracy. The accuracy of forecast can be improved by considering higher number of factors and higher dependence on history.

Now we present an extended method for handling forecasting problems based on $\mathrm{m}$-factors high-order fuzzy time series. The proposed method is now presented as follows.

Step 1) Initialize the PSO parameters (weight factor, acceleration factor and maximum iteration) with the predefined values and generate initial random velocity and position of all particles. Divide the particle into two parts. Each part consist of $n-1$ ' $\mathrm{X}$ ' and $\mathrm{m}-1$ ' $\mathrm{Y}$ ', where the $\mathrm{X}$ means the main-factor's each interval and the $\mathrm{Y}$ means the secondfactor's each interval. In the sequence, the format of each particle is represented as follows: where $x_{i}^{(1)} \leq x_{i}^{(2)} \leq \ldots \leq x_{i}^{(n-1)}$ and $y_{i}^{(1)} \geq y_{i}^{(2)} \geq \ldots \geq y_{i}^{(m-1)}$, for $\mathrm{i}=1,2, \ldots, \mathrm{c} ; \mathrm{c}$ is a swarm size.

Step 2) Take particles one by one and using values of first part define the universe of discourse $U$ of the main factor $U=\left[D_{\min }-D_{1}, D_{\max }-D_{2}\right], \quad$ where $\quad D_{\min }$ and $D_{\max }$ are the minimum and the maximum values of the main factor of the known historical data, respectively, and D1, D2 are two proper positive real numbers to divide the universe of discourse into $n$ equal length intervals $u_{1}, u_{2}, \ldots, u_{l}$. Similarly by using values of second part of particle define the universes of discourse $\mathbf{V}_{i}, i=1,2, \ldots, m-1 \quad$ of $\quad$ the secondary-factors $\mathbf{V}_{i}=\left[\left(\mathbf{E}_{\mathbf{i}}\right)_{\min }-\mathbf{E}_{i 1},\left(\mathbf{E}_{\mathbf{i}}\right)_{\max }-\mathbf{E}_{i 2}\right], \quad$ where $\left(\mathbf{E}_{\mathbf{i}}\right)_{\min }=\left[\left(E_{1}\right)_{\min },\left(E_{2}\right)_{\min }, \ldots,\left(E_{m}\right)_{\min }\right] \quad$ and $\left(\mathbf{E}_{\mathbf{i}}\right)_{\max }=\left[\left(E_{1}\right)_{\max },\left(E_{2}\right)_{\max }, \ldots,\left(E_{m}\right)_{\max }\right]$ are the minimum and maximum values of the secondary-factors of the known historical data, respectively, and $\mathbf{E}_{\mathbf{i 1}}, \mathbf{E}_{\mathbf{i} \mathbf{2}}$ are vectors of proper positive numbers to divide each of the universe of discourse $\mathbf{V}_{i}, i=1,2, \ldots, m-1$ into equal length intervals termed as $\mathbf{v}_{1, l}, \mathbf{v}_{2, l}, \ldots, \mathbf{v}_{m-1, l}, l=1,2, \ldots, p$, where $\mathbf{v}_{1, l}=\left[\mathbf{v}_{1,1}, \mathbf{v}_{1,2}, \ldots \mathbf{v}_{1, p}\right]$ represents $\mathrm{n}$ intervals of equal length of universe of discourse $\mathbf{V}_{\mathbf{1}}$ for first secondaryfactor fuzzy time series. Thus we have $(m-1) \times l$ matrix of intervals for secondary-factors.

Step 3) Define the linguistic term $A_{i}$ represented by fuzzy sets of the main factor shown as follows: 
$A_{1}=1 / u_{1}+0.5 / u_{2}+0 / u_{3}+0 / u_{4}+\ldots+0 / u_{l-2}+0 / u_{l-1}$ $A_{2}=0.5 / u_{1}+1 / u_{2}+0.5 / u_{3}+0 / u_{4}+\ldots+0 / u_{l-2}+0 / u_{l-1}$

$A_{n}=0 / u_{1}+0 / u_{3}+0 / u_{4}+\ldots+0 / u_{l-2}+0.5 / u_{l-1}+1 / u_{l}$

Similarly, for ith secondary fuzzy time series, we define the linguistic term $\quad B_{i, j}, i=1,2, \ldots, m-1, j=1,2, \ldots, n$ represented by fuzzy sets of the secondary-factors,

$B_{i, 1}=1 / \mathbf{v}_{i, 1}+0.5 / \mathbf{v}_{i, 2}+0 / \mathbf{v}_{i, 3}+0 / \mathbf{v}_{i, 4}+\ldots+0 / \mathbf{v}_{i, l-1}+0 / \mathbf{v}_{i, l}$ $B_{i, 2}=0.5 / \mathbf{v}_{i, 1}+1 / \mathbf{v}_{i, 2}+0.5 / \mathbf{v}_{i, 3}+0 / \mathbf{v}_{i, 4}+\ldots+0 / \mathbf{v}_{i, l-1}+0 / \mathbf{v}_{i, l}$

$B_{i, n}=0 / \mathbf{v}_{i, 1}+0 / \mathbf{v}_{i, 2}+0 / \mathbf{v}_{i, 3}+\ldots+0 / \mathbf{v}_{i, l-2}+0.5 / \mathbf{v}_{i, l-1}+1 / \mathbf{v}_{i, l}$

Step 4) Fuzzify the historical data described as follows. Find out the interval $u_{l}, l=1,2, \ldots, p$ to which the value of the main factor belongs. Table 2 shows Fuzzified yearly data for accidents mortalities.

Case 1) If the value of the main factor belongs to $u_{1}$, then the value of the main factor is fuzzified into $1 / A_{1}+0.5 / A_{2}+0.0 / A_{3}$, denoted by $X_{1}$.

Case 2) If the value of the main factor belongs to $u_{l}, l=2,3, \ldots, p-1$ then the value of the main factor is fuzzified into $0.5 / A_{i-1}+1 / A_{i}+0.5 / A_{i+1}$, denoted by $X_{i}$.

Case 3) If the value of the main factor belongs to $u_{p}$, then the value of the main factor is fuzzified into $0 / A_{n-2}+0.5 / A_{n-1}+1 / A_{n}$, denoted by $X_{n}$.

Now, for ith secondary-factor, find out the interval $\mathbf{V}_{i, l}$ to which the value of the secondary-factor belongs.

Case 1) If the value of the ith secondary-factor belongs to $\mathbf{V}_{i, 1}$, then the value of the secondary-factor is fuzzified into $1 / B_{i, 1}+0.5 / B_{i, 2}+0 / B_{i, 3}, \quad$ denoted by $\mathbf{Y}_{i, 1}=\left[Y_{1,1}, Y_{2,1}, \ldots, Y_{m-1,1}\right]$.

Case 2) If the value of the ith secondary-factor belongs to $\mathbf{v}_{i, l}, l=2,3, \ldots, p-1$, then the value of the ith secondaryfactor is fuzzified into $0.5 / B_{i, j-1}+1 / B_{i, j}+0.5 / B_{i, j+1}, j=i=2,3, \ldots, n-1 \quad$ denoted by $Y_{i, j}$, where $j=2,3, \ldots ., n-1$.
Case 3) If the value of the ith secondary-factor belongs to $\mathbf{V}_{i, p}$, then the value of the secondary-factor is fuzzified into $0 / B_{i, n-2}+0.5 / B_{i, n-1}+1 / B_{i, n}$, denoted by $Y_{i, n}$.

Step 5) Get the m-factors kth-order fuzzy logical relationships based on the fuzzified main and secondary factors from the fuzzified historical data obtained in Step 3).

Table 2. Fuzzified yearly data for mortality accidents from 1974 to 2004

\begin{tabular}{lll}
\hline \hline Year & $\begin{array}{l}\text { Mortality } \\
\text { Accidents }\end{array}$ & Fuzzified Mortality Accidents \\
\hline 2004 & 953 & $0.5 / \mathrm{A} 1+1.0 / \mathrm{A} 2+0.5 / \mathrm{A} 3(\mathrm{X} 2)$ \\
2003 & 1,035 & $0.5 / \mathrm{A} 1+1.0 / \mathrm{A} 2+0.5 / \mathrm{A} 3(\mathrm{X} 2)$ \\
2002 & 1,145 & $0.5 / \mathrm{A} 2+1.0 / \mathrm{A} 3+0.5 / \mathrm{A} 4(\mathrm{X} 3)$ \\
2001 & 1,288 & $0.5 / \mathrm{A} 4+1.0 / \mathrm{A} 5+0.5 / \mathrm{A} 6(\mathrm{X} 5)$ \\
2000 & 1,253 & $0.5 / \mathrm{A} 4+1.0 / \mathrm{A} 5+0.5 / \mathrm{A} 6(\mathrm{X} 5)$ \\
1999 & 1,173 & $0.5 / \mathrm{A} 3+1.0 / \mathrm{A} 4+0.5 / \mathrm{A} 5(\mathrm{X} 4)$ \\
1998 & 1,224 & $0.5 / \mathrm{A} 3+1.0 / \mathrm{A} 4+0.5 / \mathrm{A} 5(\mathrm{X} 4)$ \\
1997 & 1,150 & $0.5 / \mathrm{A} 3+1.0 / \mathrm{A} 4+0.5 / \mathrm{A} 5(\mathrm{X} 4)$ \\
1996 & 1,122 & $0.5 / \mathrm{A} 2+1.0 / \mathrm{A} 3+0.5 / \mathrm{A} 4(\mathrm{X} 3)$ \\
1995 & 1,228 & $0.5 / \mathrm{A} 3+1.0 / \mathrm{A} 4+0.5 / \mathrm{A} 5(\mathrm{X} 4)$ \\
1994 & 1,415 & $0.5 / \mathrm{A} 5+1.0 / \mathrm{A} 6+0.5 / \mathrm{A} 7(\mathrm{X} 6)$ \\
1993 & 1,346 & $0.5 / \mathrm{A} 4+1.0 / \mathrm{A} 5+0.5 / \mathrm{A} 6(\mathrm{X} 5)$ \\
1992 & 1,380 & $0.5 / \mathrm{A} 5+1.0 / \mathrm{A} 6+0.5 / \mathrm{A} 7(\mathrm{X} 6)$ \\
1991 & 1,471 & $0.5 / \mathrm{A} 6+1.0 / \mathrm{A} 7+0.5 / \mathrm{A} 8(\mathrm{X} 7)$ \\
1990 & 1,574 & $0.0 / \mathrm{A} 6+0.5 / \mathrm{A} 7+1.0 / \mathrm{A} 8(\mathrm{X} 8)$ \\
1989 & 1,488 & $0.5 / \mathrm{A} 6+1.0 / \mathrm{A} 7+0.5 / \mathrm{A} 8(\mathrm{X} 7)$ \\
1988 & 1,432 & $0.5 / \mathrm{A} 5+1.0 / \mathrm{A} 6+0.5 / \mathrm{A} 7(\mathrm{X} 6)$ \\
1987 & 1,390 & $0.5 / \mathrm{A} 5+1.0 / \mathrm{A} 6+0.5 / \mathrm{A} 7(\mathrm{X} 6)$ \\
1986 & 1,456 & $0.5 / \mathrm{A} 6+1.0 / \mathrm{A} 7+0.5 / \mathrm{A} 8(\mathrm{X} 7)$ \\
1985 & 1,308 & $0.5 / \mathrm{A} 4+1.0 / \mathrm{A} 5+0.5 / \mathrm{A} 6(\mathrm{X} 5)$ \\
1984 & 1,369 & $0.5 / \mathrm{A} 5+1.0 / \mathrm{A} 6+0.5 / \mathrm{A} 7(\mathrm{X} 6)$ \\
1983 & 1,479 & $0.5 / \mathrm{A} 6+1.0 / \mathrm{A} 7+0.5 / \mathrm{A} 8(\mathrm{X} 7)$ \\
1982 & 1,464 & $0.5 / \mathrm{A} 6+1.0 / \mathrm{A} 7+0.5 / \mathrm{A} 8(\mathrm{X} 7)$ \\
1981 & 1,564 & $0.0 / \mathrm{A} 6+0.5 / \mathrm{A} 7+1.0 / \mathrm{A} 8(\mathrm{X} 8)$ \\
1980 & 1,616 & $0.0 / \mathrm{A} 6+0.5 / \mathrm{A} 7+1.0 / \mathrm{A} 8(\mathrm{X} 8)$ \\
1979 & 1,572 & $0.0 / \mathrm{A} 6+0.5 / \mathrm{A} 7+1.0 / \mathrm{A} 8(\mathrm{X} 8)$ \\
1978 & 1,644 & $0.0 / \mathrm{A} 6+0.5 / \mathrm{A} 7+1.0 / \mathrm{A} 8(\mathrm{X} 8)$ \\
1977 & 1,597 & $0.0 / \mathrm{A} 6+0.5 / \mathrm{A} 7+1.0 / \mathrm{A} 8(\mathrm{X} 8)$ \\
1976 & 1,536 & $0.5 / \mathrm{A} 6+1.0 / \mathrm{A} 7+0.5 / \mathrm{A} 8(\mathrm{X} 7)$ \\
1975 & 1,460 & $0.5 / \mathrm{A} 6+1.0 / \mathrm{A} 7+0.5 / \mathrm{A} 8(\mathrm{X} 7)$ \\
1974 & 1,574 & $0.0 / \mathrm{A} 6+0.5 / \mathrm{A} 7+1.0 / \mathrm{A} 8(\mathrm{X} 8)$ \\
\hline \hline & &
\end{tabular}

If the fuzzified historical data of the main-factor of ith day is $X_{i}$, then construct the m-factors kth-order fuzzy logical relationships,

$\left(X_{j-k} ; Y_{2, j-k}, \ldots, Y_{m-1, j-k}\right), \ldots,\left(X_{j-2} ; Y_{2, j-2}, \ldots, Y_{m-1, j-2}\right)$,
$\left(X_{j-1} ; Y_{1, j-1}, Y_{2, j-1}, \ldots, Y_{m-1, j-1}\right), \rightarrow X_{j}$

where $j>k . X_{j-k}$ shows the k-step dependence of jth value of main factor $\quad X_{j}$, $Y_{i, j-k}, i=1, \ldots, m-1, j=1, \ldots, k$. Then, divide the derived fuzzy logical relationships into fuzzy logical relationship 
groups based on the current states of the fuzzy logical relationships. The secondary factors acts like a secondary component to the m-dimensional state vector.

Step 6) For m-factor kth order fuzzy logical relationship, the forecasted value of day $\mathrm{j}$ based on history of third order is calculated as follows,

$t_{j}=\frac{\sum_{j-1}^{j+1} w}{\frac{w_{j-1}}{a_{j-1}}+\frac{w_{j}}{a_{j}}+\frac{w_{j+1}}{a_{j+1}}}$

Where $a_{l-1, a_{l}}$ and $a_{l+1}$ are the midpoints of the intervals $u_{l-1,} u_{l}$ and $u_{l+1}$ respectively. Above forecasting formula fulfills the axioms of fuzzy sets like monotonicity, boundary conditions, continuity and idempotency. For measurement of accuracy of forecasting for fuzzy time series forecasting, we use average forecasting error rate (AFER) as the performance criteria, defined as

$$
A F E R=\frac{\sum_{i=1}^{n}(\mid \text { Forecated value of day } j-\text { Actual value of day } j \mid / \text { Actual value of day } j)}{n} \times 100 \%
$$

Step 7) Compare AFER value of current particle with local best particle's AFER value and set current particle as local best in case current AFER is lower than local best AFER value.

Step 8) Repeat steps 2 to 7 for all the particles in swarm, and now pick up the particle with minimum AFER from all the particles' local bests. Set this as global best particle.

Step 9) For each particle, calculate particle velocity according to Eq.

$v_{i}^{(t+1)}=w^{(t)} \times v_{i}^{(t)}+c_{1} \times r_{1} \times\left(\right.$ pbest $\left.-x_{i}^{(t)}\right)+c_{2} \times r_{2} \times\left(\right.$ gbest $\left.-x_{i}^{(t)}\right)$

This is based on the gbest and the pbest values and then update particle position according to Eq

$x_{i}^{(t+1)}=x_{i}^{(t)}+v_{i}^{(t+1)}$

This step will lead the each particle to a more promising solution for optimal tuning of two-factors nth-order fuzzy time series.

Step 10) Update the value of the weight factor $w$ according to Eq.

$w^{(t)}=w_{\max }-t \times\left(w_{\max }-w_{\min }\right) /$ iter $r_{\max }$

Step 11) Stop if the stop criterion of the PSO, the maximum number of iteration, is satisfied. Otherwise, go to Step 2. The final gbest value after stopping PSO iterations will be our required result

\section{EXPERIMENT}

We have applied this new technique on car road accident data taken from National Institute of Statistics, Belgium for the period of 1974-2005. In this data, the main factor of interest is the yearly road accident casualties and secondary factors are mortally wounded, died within one month, severely wounded and light casualties. We have used 11 particles in a swarm and executed PSO for 500 iterations to get best results.

We assumed eight intervals of equal length for the main and secondary fuzzy time series'. For main factor, we assume $D_{\min }=953$ and $D_{\max }=1644$, thus for main factor time series we get $U=[850,1650]$. Similarly for secondary factors $Y_{1}, Y_{2}, Y_{3}$ and $Y_{4}$, we assumed that $\mathbf{E}_{\min }=[90,1094,5949,38390]$ and $\mathbf{E}_{\max }=[819,2393,16645,46818]$

Table 3. Forecasted yearly car road accident casualties from 1974-2004

\begin{tabular}{ccc|c}
\hline \hline & & & $F_{i}-A_{i}$ \\
Actual & Forecasted & Fi - Ai & $A_{i}$ \\
\hline 953 & Kills Fi & & \\
\hline 1,035 & 1022.684 & -12.316 & 0.01189952 \\
1,145 & 1155.396 & 10.396 & 0.00907948 \\
1,288 & 1318.751 & 30.751 & 0.023875 \\
1,253 & 1231.045 & -21.955 & 0.01752195 \\
1,173 & 1155.396 & -17.604 & 0.01500767 \\
1,224 & 1231.045 & 7.045 & 0.00575572 \\
1,150 & 1155.396 & 5.396 & 0.00469217 \\
1,122 & 1092.966 & -29.034 & 0.02587701 \\
1,228 & 1231.045 & 3.045 & 0.00247964 \\
1,415 & 1399.624 & -15.376 & 0.01086643 \\
1,346 & 1318.751 & -27.249 & 0.02024443 \\
1,380 & 1399.624 & 19.624 & 0.01422029 \\
1,471 & 1483.872 & 12.872 & 0.00875051 \\
1,574 & 1561.875 & -12.125 & 0.0077033 \\
1,488 & 1483.872 & -4.128 & 0.00277419 \\
1,432 & 1399.624 & -32.376 & 0.02260894 \\
1,390 & 1399.624 & 9.624 & 0.00692374 \\
1,456 & 1483.872 & 27.872 & 0.01914286 \\
1,308 & 1318.751 & 10.751 & 0.00821942 \\
1,369 & 1318.751 & -50.249 & 0.03670489 \\
1,479 & 1483.872 & 4.872 & 0.00329412 \\
1,464 & 1483.872 & 19.872 & 0.01357377 \\
1,564 & 1561.875 & -2.125 & 0.0013587 \\
1,616 & 1561.875 & -54.125 & 0.03349319 \\
1,572 & 1561.875 & -10.125 & 0.00644084 \\
\hline & 1561.875 & -82.125 & 0.04995438 \\
\hline & 1561.875 & -35.125 & 0.02199436
\end{tabular}


1,536

1,460

1,574
$-$

$--$

to determine $\mathbf{v}_{1}, \mathbf{v}_{2}, \mathbf{v}_{3}, \mathbf{v}_{4}$. Selection of $D_{\min }, D_{\max }$, $\mathbf{E}_{\text {min }}$ and $\mathbf{E}_{\text {max }}$ have significant effects on the accuracy of this new method.

We can introduce learning to stabilize the heuristic selection of these constants.

Using (8) and (9), we formed fuzzy times series from main and secondary factors. Therefore, each observation of a time series is now represented by a combination of fuzzy sets. Using (11), we calculated the forecasted values corresponding to each actual value of the main factor time series in Table 3 . Using equation (12) for AFER, we formed Table 4, showing a comparison of actual and forecasted values. Finally, we have red proposed method with [4].

\section{CONCLUSION}

From Table 4, we can see that our proposed method is better that Lee, Wang Chen [4]. As the work of Lee, Wang Chen [4] outperformed the work of Huarng ([2], [19]) and Chen [3] so indirectly we can conclude that our general class of methods for fuzzy time series modeling and forecasting.

Furthermore, we have shown fuzziness of fuzzy observations by presenting each datum of the main series as composed of many fuzzy sets. Thus, fuzzy time series modeling extends to type-II fuzzy time series modeling. The type-II defuzzified forecasted values $\left(t_{j}\right)$ may also be calculated using some other method, e.g. learning rules from fuzzy time series.

TABLE 4. Comparison of proposed method with other researches for yearly car road accident casualties in Belgium 1974-2004

\begin{tabular}{ll}
\hline \hline \multicolumn{1}{c}{ Reference } & \multicolumn{1}{c}{ AFER } \\
\hline Jilani and Burney (2008) & $2.06 \%$ \\
Jilani and Burney (2008) & $4.69 \%$ \\
Lee et. Al (2006) & $4.72 \%$ \\
Lee L.W. (2006) & $5.07 \%$ \\
Jilani and Burney (2007) & $5.06 \%$ \\
Proposed Method & $\mathbf{1 . 4 9 \%}$
\end{tabular}

\section{ACKNOWLEDGMENTS}

The work is completed with partial support from Higher Education Commission of Pakistan and Dean Faculty of Science, University of Karachi.

\section{REFERENCES}

[1] Q. Song and B. S. Chissom 1993a "Forecasting Enrollments with Fuzzy Time Series-Part I", Fuzzy Sets and System, Vol. 54, No. 1, pp. 1-9.

[2] K. Huarng, 2001a "Heuristic models of fuzzy time series for forecasting," Fuzzy Sets and Systems, Vol. 123, No. 3, pp. 369-386.

[3] S. M. Chen, 2002 "Forecasting Enrollments Based on High-Order Fuzzy Time Series", Cybernetic Systems, Vol. 33, No. 1, pp. 1-16.
[4] L. W. Lee, L. W. Wang, S. M. Chen, Jun. 2006 "Handling Forecasting Problems Based on Two-Factors High-Order Time Series", IEEE Transactions on Fuzzy Systems, Vol. 14, No. 3, pp.468-477.

[5] Melike Sah and Y. D. Konstsntin, 2004 "Forecasting Enrollment Model based on first-order fuzzy time series", Published in proc., International Conference on Computational Intelligence, Istanbul, Turkey.

[6] T. A. Jilani, S. M. A. Burney and C. Ardil, 2007a "Fuzzy metric approach for fuzzy time series forecasting based on frequency density based partitioning", International Journal of Computational Intelligence, Vol. 4, No. 2, pp $12-18$.

[7] T. A. Jilani, S. M. A. Burney, 2007b "M-Factor High Order Fuzzy Time Series Forecasting for Road Accident Data", Advances in Soft Computing vol. 41, pp.246257.

[8] T. A. Jilani, S. M. A. Burney, 2008a "Multivariate High Order Fuzzy Time Series Forecasting for Car Road Accidents", International Journal of Computational Intelligence, Vol. 4, No. 1, pp. 15-20.

[9] T. A. Jilani, S. M. A. Burney, 2008b "Multivariate stochastic fuzzy forecasting models", Expert Systems With Applications, vol. 37 No. 2, pp. 691-700.

[10] H. J. Zimmerman, 2001 "Fuzzy set theory and its applications", Kluwer Publishers, Boston, MA.

[11] H. Ishibuchi, R. Fujioka and H. Tanaka, 1993 "Neural Networks that Learn from Fuzzy If-Then Rules", IEEE Transactions on Fuzzy Systems, Vol. 1, No. 1, pp.85-97.

[12] G. J. Klir and B. Yuan, 2005 "Fuzzy Sets and Fuzzy Logic: Theory and Applications", Prentice Hall, India, Ch. 4.

[13] R. R. Yager and P. P. D. Filev, 2002 "Essentials of Fuzzy Modeling and Control", John Wiley and Sons, Inc.

[14] B. J. MacLennan, 2004, "Natural computation and nonturing models of computation", Theoretical Computer Science, (1-3), pp. 115-145.

[15] P. Marrow, 2000 "Nature-inspired computing technology and applications". BT Technology Journal (4), pp. 13-23.

[16] A. P. Deweijer, C. B. Lucasius, L. Buydens 1994, "Curve-fitting using natural computation", Analytical Chemistry 66(1), pp. 23-31.

[17] J. Kennedy and R. Eberhart, 2001 "Swarm Intelligence". Morgan Kaufmann Publishers, Inc., San Francisco, CA.

[18] Maurice Clerc, 2006, "Particle Swarm Optimization", ISTE Ltd, USA.

[19] K. Huarng, 2001b "Effective Lengths of Intervals to Improve Forecasting in Fuzzy Time Series", Fuzzy Sets System, Vol. 123, No. 3, pp. 387-394. 